successfully operated upon in the neonatal period. Antenatal examination should be able to define the seriousness of the defect and allow discussion and consideration of the various options in the light of others' experiences. Therefore, such cases should be investigated in centres for antenatal diagnosis and individual cases managed on their own merits, allowing for the particular circumstances of the case.

\section{References}

1 Bergsma D, ed. Birth defects compendium. 2nd ed. New York: MacMillan Press, 1979:948.

2 Schmid W, Mühlethaler JP. High amniotic fluid alphafetoprotein in a case of fetal sacrococcygeal teratoma. Humangenetik $1975 ; 26: 353-4$.

${ }^{3}$ Report of the Collaborative Acetylcholinesterase Study. Amniotic fluid acetylcholinesterase electrophoresis as a secondary test in the diagnosis of anencephaly and open spina bifida in early pregnancy. Lancet 1981;ii:321-4.

${ }^{4}$ Feige A, Gill J, Vonmaill K, Mulz D. Pränatale Diagnostik eines Steissbeinteratoms mit Hypertrophie der Plazenta. Geburtshilfe Frauenheilkd 1982;42:20-4.
${ }^{5}$ Hecht F, Hecht BK, O'Keeffe D. Sacrococcygeal teratoma: prenatal diagnosis with elevated alpha-fetoprotein and acetyl- $\overrightarrow{\overline{\vec{S}}}$ cholinesterase in amniotic fluid. Prenatal Diagnosis 1982;2: 229-31.

${ }^{6}$ Horger EO, McCarter LM. Prenatal diagnosis of sacrococcygeal teratoma. Am J Obstet Gynecol 1979;134:228-9.

7 Papp Z, Polgár K, Tóth Z, Csécsei K. Prenatal diagnosis of neural tube defects by exfoliative cytology of amniotic fluid. $\varrho$ Acta Cytol (Baltimore) 1982;26:751-2.

${ }^{8}$ Polgár K, Sipka S, Ábel GY, Papp Z. Neutral-red uptake by amniotic fluid macrophages in neural tube defects: a rapid test. $\overrightarrow{0}$ N Engl J Med 1984;310:1463-4.

${ }^{9}$ Brock DJH, Richmond DH, Listen WA. Normal second- $\vec{\omega}$ trimester amniotic fluid alpha-fetoprotein and acetylcholinester- $S$ ase associated with fetal sacrococcygeal teratoma. Prenatal $\overline{3}$
Diagnosis 1983;3:343-5.

${ }^{10}$ Kohn J, Orr H, McElwain TJ, Bentall M, Peckham MJ. Serum N alphafetoprotein in patients with testicular tumours. Lancet or 1976;ii:433-5.

Correspondence and requests for reprints to Dr Z Papp, University Department of Obstetrics 9 and Gynaecology, Medical School, Debrecen, $\vec{\circ}$ H-4012 Hungary.

\title{
The Nager acrofacial dysostosis syndrome with the tetralogy of Fallot
}

\author{
E THOMPSON*, R CADBURY†, AND M BARAITSER* \\ ${ }^{*}$ Clinical Genetics Department, The Hospital for Sick Children, Great Ormond Street, London WC1N 3JH; \\ and +Queen Elizabeth Hospital for Children, Hackney Road, London E2 8PS.
}

SUMMARY A male infant is described with mandibulofacial dysostosis and absent thumbs, consistent with the Nager acrofacial dysostosis syndrome. In addition, the tetralogy of Fallot was present. Major congenital heart malformations occur rarely in this syndrome.

The Nager acrofacial dysostosis (AFD) syndrome, originally described by Nager and de Reynier ${ }^{1}$ in 1948 , is characterised by mandibulofacial dysostosis with radial defects. The facial appearance is similar to the Treacher-Collins syndrome with antimongoloid eye slant, malar and mandibular hypoplasia, and ear hypoplasia. The radial defect involved thumb aplasia or hypoplasia in all cases reviewed by Halal $e t a l^{2}$ and was associated with aplasia or hypoplasia of the radius or with radioulnar synostosis in half. The precise mode of inheritance of the Nager syndrome remains unclear, as discussed by Pfeiffer and Stoess. ${ }^{3}$ There is evidence for autosomal recessive inheritance (reports of affected sibs in two families) and for autosomal dominant inheritance (three families with advanced paternal age suggesting new dominant mutation).

Received for publication 8 November 1984. Accepted for publication 2 January 1985.
The heart is usually normal in Nager syndrome. $\frac{\mathscr{Q}}{\Phi}$ Exceptions include reports in which the heart defect is minimal or the case is atypical of Nager syndrome, which we discuss.

We present a clear cut case of Nager syndrome with a congenital heart defect.

\section{Case report}

The patient, a male, was the only child of an unrelated healthy Nigerian father and West Indian $\delta$ mother. At the time of conception, the mother was aged 19 years and the father was aged 31 years. $\mathrm{He}$ 욱 had been undergoing investigations for oligo- $\supset$ spermia. During the pregnancy the mother had remained healthy apart from vomiting at eight $\bar{N}$ weeks for which metoclopramide was given orally. At 30 weeks' gestation, an ultrasound scan was done $\tilde{O}$ and showed polyhydramnios. The baby was born by rapid spontaneous vaginal delivery on the same day. The Apgar score at one minute was 5. The five 0 minute Apgar was 9, following administration of oxygen via a face mask. The gestational age was $\stackrel{\oplus}{+}$ assessed as 30 weeks by Dubowitz criteria. At birth, $T$ the weight was $1070 \mathrm{~g}$ (10th centile), the length 40 웅 cm (25th centile), and the head circumference $28 \mathrm{~cm} \stackrel{\triangle}{\Omega}$ (50th centile). The following abnormalities were $\mathbb{8}$ noted (fig 1): severe micrognathia, malar hypo- 


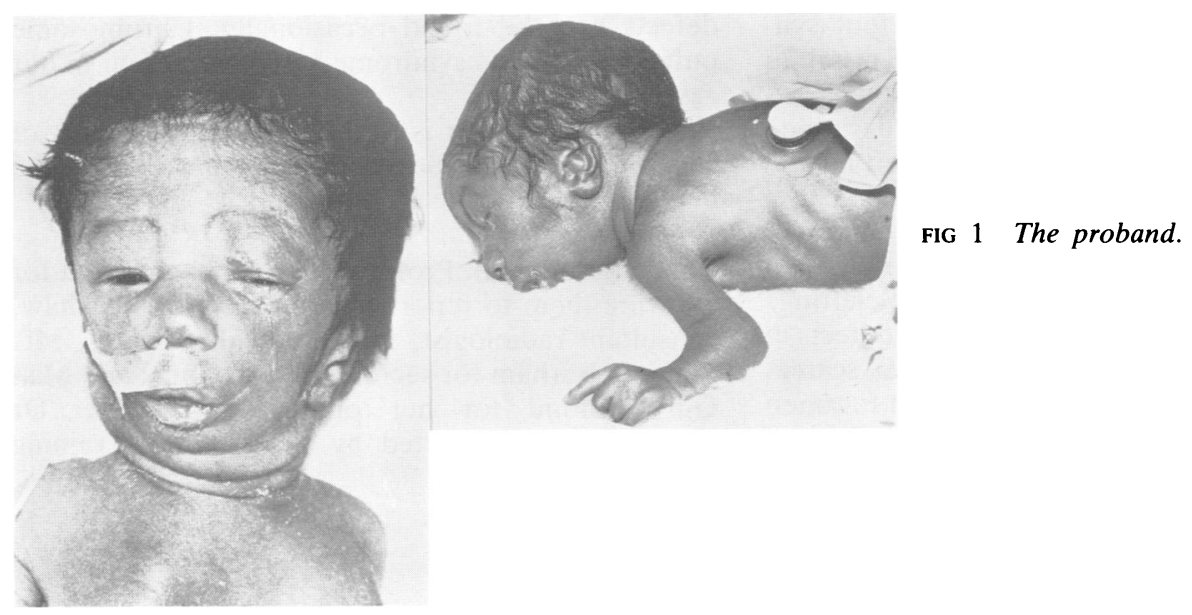

plasia, low set hypoplastic ears, and downward slanting palpebral fissures. The palate was intact. The thumbs were absent and there was camptodactyly of the middle and ring fingers bilaterally (fig 2). The forearms were shortened and there was skin webbing at the elbows. The right forearm could not be supinated but could be fully pronated; the left could be supinated to a limited degree. The feet were normal.

During the first day of life episodes of cyanosis occurred and a cardiac murmur developed. A chest $x$-ray showed cardiomegaly. Two dimensional echocardiography revealed a large ventricular septal defect, an overriding aorta with a left arch, and confluent normally sized pulmonary arteries, consistent with the diagnosis of tetralogy of Fallot. A moderate sized patent ductus arteriosus was present. $X$-rays of the limbs showed absent first metacarpals and thumbs and shortened radii and ulnae. There was no radioulnar synostosis (fig 3 ). Chromosome karyotype ( $\mathrm{G}$ banded) was normal $46, X Y$. Chromosome puffs were sought and were absent.

On the second day the blood picture revealed a haemoglobin of $19.9 \mathrm{~g} / \mathrm{dl}$ and white cell count $21 \cdot 5$

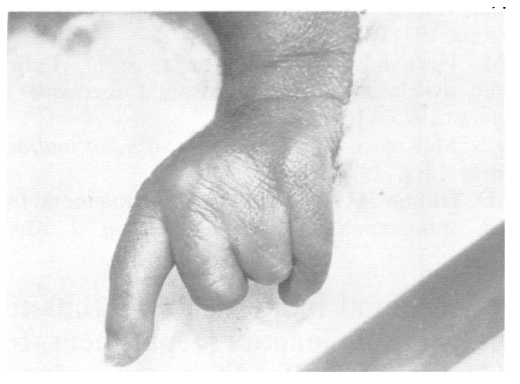

FIG 2 Proband's hand.

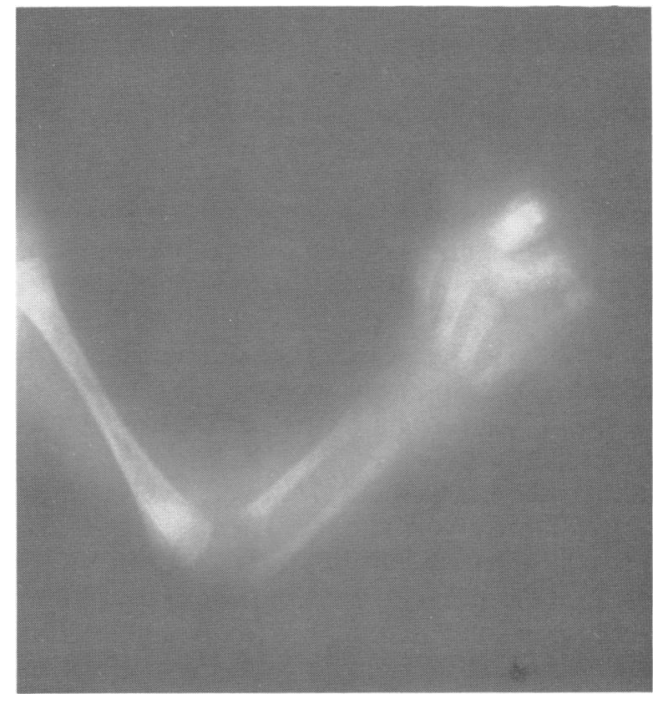

FIG $3 X$-ray of left arm. Note absent thumb and short radius.

$10^{y} / 1$ with $6 \%$ neutrophils, $29 \%$ lymphocytes, $10 \%$ monocytes, and no eosinophils. The platelet count was low at $7610^{9} / 1$ (normal range 100 to $250 \times 10^{9} / 1$ ) but is probably a non-specific finding in a sick preterm infant. Recurrent episodes of cyanosis occurred and the child died on day 16. Permission was not given for necropsy.

\section{Discussion}

The child described had typical facial and limb features of the Nager AFD syndrome. Three AFD syndromes listed by Halal et $a l^{2}$ and two others are excluded in our patient as follows. (1) The postaxial AFD syndrome by the predominantly radial defect. ${ }^{4}$ 
(2) The autosomal dominant AFD split foot syndrome by the normal feet. ${ }^{5}$ (3) The AFD distal $2 q$ duplication syndrome by the normal karyotype. ${ }^{6}(4)$ The AFD triphalangeal thumb syndrome described by Richieri-Costa et al by the absence of cleft lip and palate and lack of the characteristic thumb anomaly. ${ }^{7}$

(5) The very severe AFD described in two unrelated patients by Kawira $e t a l^{8}$ involved severe reduction defects of all four limbs with severe facial clefting.

Well defined reports of congenital heart defects in typical cases of Nager syndrome are scarce. Schönenberg ${ }^{9}$ reported a case with a patent foramen ovale, but since this finding occurs in up to $20 \%$ of normal persons, it is not generally considered to be a true malformation. ${ }^{10}$

A child of a Puerto-Rican consanguineous couple, described by Burton and Nadler, ${ }^{11}$ had facial features of Nager syndrome with radial limb reduction defects but with unilateral ectrodactyly in one hand. This atypical case was associated with an undefined cardiac murmur, and was called AFD cardiomelic syndrome by Richieri-Costa et al. ${ }^{7}$ Sugiura $^{12}$ reported a Japanese boy with left hemifacial microsomia, absent left radius and thumb, dextrocardia with a ventricular septal defect, and crossed renal ectopia. There were minimal malformations on the right side, namely a right 'pocket ear' and a hypoplastic right thenar muscle. It is less likely that this represents Nager syndrome than hemifacial microsomia with radial defects of which there are other reports. ${ }^{2}$ One of the two neonates with severe AFD reported by Kawira et al ${ }^{\gamma}$ had a ventricular septal defect. However, the severity of face and limb involvement in these cases suggests they are a separate entity from Nager syndrome.

The faciocardiomelic syndrome described in three sons of a consanguineous Mexican couple by Cantú et $a l^{13}$ bears some resemblance to the present case. Similarities include micrognathia, abnormal ears, radial hypoplasia, hypoplastic thumbs, and congenital heart disease, namely left heart hypoplasia. What distinguishes the faciocardiomelic syndrome from the present case are a very small mouth, lack of malar hypoplasia, and normally slanting palpebral fissures.

Numerous syndromes involve radial reduction defects and congenital heart lesions, but are readily distinguished from the present case by normal facial appearance or additional features. These include the Holt-Oram syndrome, the Aase-Smith syndrome, the Fanconi syndrome, the TAR syndrome, and the VATER association. ${ }^{14}$ Features of the autosomal recessive Roberts syndrome include orofacial defects and hypomelia. The latter may be phocomelia of all four limbs; less severe limb abnormalities include absent or malformed thumb or radial aplasia. Heart defects may be found occasionally. Chromosome puffs occur in this syndrome and were absent in our case. ${ }^{15}$

The present case is probably the first report of classic Nager syndrome associated with a documented major congenital heart defect.

The authors thank Professor Christopher Wood for allowing them to report this case, Dr David Shaw, consultant radiologist, for helpful discussions, Mrs Melanie Barham for secretarial assistance, and Miss Gill Almond for her photographic work. Dr Thompson is supported by a Wellcome Training Fellowship.

\section{References}

' Nager FR, de Reynier JP. Das Gehörorgan bei den augeborenen kopfmissbildungen. Pract Oto-Rhino-Laryngol 1948;10(suppl 2):1-128.

2 Halal F, Herrmann J, Pallister PD, Opitz JM, Desgranges MF, Grenier G. Differential diagnosis of Nager acrofacial dysostosis syndrome: report of four patients with Nager syndrome and discussion of other related syndromes. Am J Med Genet 1983;15:209-24.

${ }^{3}$ Pfeiffer RA, Stoess H. Acrofacial dysostosis (Nager syndrome): synopsis and report of a new case. Am J Med Genet 1983;15:255-60.

${ }^{4}$ Miller M, Fineman R, Smith DW. Postaxial acrofacial dysostosis syndrome. $J$ Pediatr 1979;95:970-5.

${ }^{5}$ Fontaine G, Farriaux JP, Delattre P, et al. Une observation familiale du syndrome ectrodactylie et dysostose mandibulofaciale. J Genet Hum 1974;22:289-307.

6 Wagner SF, Cole J. Nager syndrome with partial duplication of the long arm of chromosome 2. Am J Hum Genet 1979;31:116A.

7 Richieri-Costa A, Gollop TR, Colletto GMDD. Brief clinical report: syndrome of acrofacial dysostosis, cleft lip/palate, and triphalangeal thumb in a Brazilian family. Am J Med Gene 1983;14:225-9.

${ }^{8}$ Kawira EL, Weaver DD, Bender HA. Acrofacial dysostosis with severe facial clefting and limb reduction. Am J Med Genet 1984;17:641-7.

9 Schönenberg H. Die Differential-diagnose der radialen Defektbildungen. Paediatr Prax 1968;7:455-67.

${ }^{10}$ Rowe RD, Freedom RM, Mehrizi A. The neonate with congenital heart disease. Major problems in clinical pediatrics. 2nd ed. Vol V. Philadelphia: Saunders, 1981.

1 Burton BK, Nadler HL. Nager acrofacial dysostosis. Report of a case. J Pediatr 1977;91:84-6.

12 Sugiura Y. Congenital absence of the radius with hemifacial microsomia, ventricular septal defect and crossed renal ectopia. Birth Defects 1971;VII(7):109-16.

13 Cantú JM, Hernández A, Ramirez J, et al. Lethal faciocardiomelic dysplasia - a new autosomal recessive disorder. Birth Defects 1975;XI(5):91-8.

14 Temtamy S, McKusick V. The genetics of hand malformations. New York: Liss, 1978.

15 Tomkins D, Hunter AGW, Roberts M. Cytogenetic findings in Roberts-SC phocomelia syndrome(s). Am J Med Genet 1979;4:17-26.

Correspondence and requests for reprints to Dr E Thompson, Clinical Genetics Department, Institute of Child Health, 30 Guilford Street, London WC1N $1 \mathrm{EH}$. 